\title{
"...and beyond/ Frighted the reign of Chaos and old Night": On the Humanities (in times of) Crisis
}

\author{
Jeremy De Chavez \\ Department of English, University of Macau. ORCID: oooo-0o03-0320-372X \\ Email: jeremydechavez@um.edu.mo
}

\begin{abstract}
The history of the present is replete with the language of crisis, which has infiltrated various domains including the political, economic, social, environmental, and moral. Those various proclamations of collapse and disaster intersect somewhat in yet another crisis that we have become all too familiar with: the Humanities crisis. We are regularly reminded, and with intensifying pleas of urgency, that the Humanities are in peril. While various commentators have linked the troubling erosion of the Humanities to the present and impending failures of critical thought, democracy, and civic duty, the Humanities are still widely regarded as unable to measure up to the emerging dominant metrics of value. What then is to be done? How might we come to the defense of the Humanities without merely mouthing banal pieties or capitulating to the paralyzing force of cynical reason? Avoiding both prescriptive polemics and resignation to the corporate university's remorseless logic of markets, I offer some reflections on what might constitute a valid defense of the Humanities. I suggest a plural form of defense that does not exacerbate what C.P. Snow has called "a gulf of mutual comprehension" between "two cultures" (1963, p. 4).
\end{abstract}

Keywords: humanities crisis, Nussbaum, liberal arts, two cultures

\section{Introduction}

There is a tempest that we collectively have to weather, and that tempest is called the crisis of the Humanities. Humanities Departments are conveniently and ruthlessly caricatured as populated by beleaguered yet mulish luddites who are a drain on the economy because they shamelessly squander university money to fund frivolous obsessions. Such characterizations underscore our being out of touch, our disconnection from life, as they know it. The corporate university-its calculations, its rationalizations, its logic of markets-are anathema to what we do and to what we hold dear. And they seem to have already imagined a future, and it is a future where we no longer exist - an idea particularly insulting since we have, for the most, part convinced ourselves that we are custodians of the imagination, of fancy, and of creative and critical thinking. Judith Butler has recently observed that in subscribing to the dominant assessment regimes the intrinsic value of the Humanities might be pushed to oblivion (2014, p. 18). We are regularly reminded, and with intensifying pleas of urgency, that the Humanities are in peril. While various commentators have linked the troubling erosion of the Humanities to the present and impending failures of critical thought, democracy, and civic duty, the Humanities are still widely regarded as unable to measure up to the emerging dominant metrics of value. What then is to be done? How might we come to the defense of the Humanities without merely mouthing banal pieties or capitulating to the paralyzing force of cynical reason? How might we insist on our relevance? How might we

(C) AesthetixMS 2020. This Open Access article is published under a Creative Commons Attribution Non-Commercial 4.0 International License (http://creativecommons.org/licenses/by-nc/4.o/), which permits non-commercial re-use, distribution, and reproduction in any medium, provided the original work is properly cited. For citation use the DOI. For commercial re-use, please contact editor@rupkatha.com. 
convince the world that the future needs us? And perhaps more importantly, how might we intervene to help shape that very future?

In what follows, I offer some critical reflections on often-deployed justifications for the value of the Humanities. I focus my attention on arguments pitched at the general level while I believe that the most forceful justifications must be finally attentive to context. Defending the Humanities from its broadest to its more local iterations comprises what Helen Small has referred to as a "pluralistic account of value" (2013, p. 3), a pluralism that does not necessarily entail contradiction or incoherence. Part of the strategy is to know when to use one type of the defense over another, when to push one harder, when to tone another down. It will all depend on the nature of the threat since a strategy of defense is only effective against specific forms of attack. Much of what I will discuss will obviously be affected by numerous variables and would have to be properly calibrated. Differences in geographical location, whether you are from a publicly or privately funded university, whether you are from a Research 1 University or a Liberal Arts college, among others. In some cases, it is easier to defend the value of the Humanities at the level of general education than it is to do so as an area of research. I think it's easier for the public to understand why, say, Shakespeare should be taught (even in postcolonial universities) but it gets tougher to explain why an advanced research degree in Renaissance dramatic literature constitutes a public good. It must be said, however, that I only offer conjecture and not sustained arguments. In saying this, I avoid two modes that defenses of the Humanities usually take: the polemic and the manifesto, which seem to me to be overly impassioned but rarely convincing.

In reflecting on what might constitute a compelling defense of the Humanities, I should say that it has a proximate relation to two already well-established genres, as literary critic Helen Small notes: the "defense of poetry" (recall the work of Sir Phillip Sidney and Percy Shelley) and "the idea of the university" (Newman and more recent proponents include Readings, Menand). Small notes that the former is too restrictive in scope while the latter perhaps too broad, and that a defense of the Humanities has to be more than the first but more specific than the second. However, I have also come across arguments that suggest that the fate of the Humanities is intimately connected to the fate of the University. An example is Stanley Fish, who writes:

When it comes to justifying the humanities, the wrong questions are what benefits do you provide for society and are you cost-effective. The right question is how do you - that is, your program of research and teaching - fit into what we are supposed to be doing as a university.

Fish seems to be suggesting that perhaps our energies are better directed toward saving the university rather than necessarily a more focused defense of the Humanities.

It is not surprising that those pronouncements that the university is in ruins, to use the phrase of Bill Readings, come primarily from the Humanities where the crisis is most strongly felt. Stefan Collini even suggests that for some subject areas there is no crisis at all, unless an increase in research funding could somehow constitute a crisis. As Humanists, I think we need to do a better job in convincing our colleagues from the sciences and the social sciences of our value. This is where we need to tone down insistence of what C.P. Snow has called the "two cultures" in the university. I do not think we are served well by sustaining this adversarial mode of self-definition. I am convinced that a specific defense of the Humanities must go hand in hand with a broader defense of the idea of the University. Here I concur with Judith Butler who suggests that "by focusing on what the Humanities have to offer we start to rethink that task of the university itself" (2014, p. 19). 
3 "...and beyond/ Frighted the reign of Chaos and old Night": On the Humanities (in times of) Crisis

At this point, I would like to offer a critical review of the most common lines of defense of the Humanities. All of these arguments, pitched at the level of the general, would of course express variation when articulated in specific contexts. They are:

1. Defense of Intrinsic Value: a common line of defense but perhaps achieves in its most sophisticated articulation in the work of Butler, Spivak (Aesthetic education), and Derrida (university without condition)

2. The Profitability Defense, which often uses the language of metrics of inputs and outputs to make a case for the Humanities.

3. Democracy Needs Us Defense (Nussbaum, but also Zakaria, Giroux)

I will consider all three but spend most of my remaining time discussing the third since to me it is the argument that makes the most ambitious claim-that civilization as we know it would collapse if we do not come to the defense of the Humanities.

\section{Defense of Intrinsic Value}

This is for me the defense that comes easiest. It is the one that is immediately in my grasp when I am asked to defend the Humanities. In a way, the notion of the intrinsic value of the Humanities rests on intuition rather than being demonstrable-a reason that one just knows is there but resists clear expression. Thus, there is an almost religious quality to this argument, in that one is asked to pin one's faith in the idea that to devote oneself to the Humanities is also to offer oneself to something greater. Perhaps its simplest iteration is the argument that the Humanities are useless and should be defended as useless. Its perhaps more nuanced iterations, however, is the more palatable claim that while the Humanities might be essentially useless, its usefulness might be an incidental or even accidental aspect of its value. Versions of this argument appear quite regularly in opinion essays that one might find in the Chronicle of Higher Ed or The Guardian.

This line of argument would often elevate the Humanities as a venue to critique instrumental rationality within the walls of academia and beyond. It is a defense that clearly runs counter to the agenda of the neoliberal university in its claim that the Humanities have no economic utility and is removed from practical ends. The idea of the university, so the argument goes, is to produce reflective, critical, ethical individuals and not commodified commodityobsessed automatons. Thus, it is often invoked in arguments that critique the neoliberal university.

Judith Butler claims that the problem with insisting on "intrinsic value" is that others do not recognize that value and therefore must be demonstrated. This is where a problem arises. For "if it must be demonstrated it has to be demonstrated within a language and an idiom that can be recognized by those who most clearly need to be convinced of that value" (Butler, 2014, 27). If university administrators will only recognize the value and language of metrics, then we find ourselves again in that space called oblivion that Butler speaks about. Perhaps we can find comfort in Adorno's idea that (lyric) poetry is most valuable when "it communicates nothing" (1991, p. 43). That is to say, when it refuses the structures of communication endorsed by society, its critical potential is underscored when it "does not chime in with society" (Adorno, 1991, p. 43). In that sense there might be ironic agreement between Humanists and university administrators that the Humanities are indeed a melancholy science.

The intrinsic-value defense is perhaps the least hospitable to compromise, and therefore least compatible to a pluralistic defense of the Humanities. To defend the Humanities as laudably 
useless is to defend it absolutely and exclusively from the horizon of that position. Moderate versions of this argument-as I have mentioned, take the position that while the Humanities are admirably useless, they may have peripheral or secondary practical utility-is often seen as a betrayal of the intrinsic-value argument. It is an argument that seems to me to be convincing only to other Humanists and impressionable students, but not to university administrators and parents. Or, as Stanley Fish has pointed out, it would also be all too easy for universities to parrot our "pieties while withholding the funds". In addition, it is a line of argument that potentially reinforces the "two cultures" debate, as the useless Humanities pits itself against the more practical disciplines, the sciences and even the social sciences.

\section{The Profitability Defense}

The argument that runs counter to the idea that the Humanities are laudably useless is the "profitability defense" which, in contrast, argues that the Humanities have much to contribute to the knowledge economy. This type of defense often speaks in the tongue of instrumental reason and assessment regimes, that Judith Butler cautions us about. This line of argument aims to show that studying the Humanities, when all things are considered, is economically rewarding. It emphasizes how a Humanities education cultivates marketable skills in students.

The problem with the profitability defense is that apart from providing a convincing case that skills cultivated by a Humanities training are marketable, Humanities advocates are also pressed to argue why those skills are exclusive to a Humanities education. In the case of literary studies, the shift from a predominantly moralistic justification of the Humanities (say in the work of Matthew Arnold) to one that emphasizes the cultivation of skills (both critical and communicative) could be read as one that responds to the needs of the market. Indeed, it was newsworthy, when American billionaire investor Mark Cuban made a forecast that 10 years from now there will be a greater demand for Humanities majors. This was optimistically interpreted by some as confirming the value of the Humanities. Cuban suggests that the reason is because the future needs people with "different perspectives" and a "freer thinker".

Although the Humanities has prided itself as cultivating critical thinking and what Martha Nussbaum calls "narrative imagination" (or the ability to imagine oneself in another position), there is a questionable assumption of privilege in claiming those over other fields (2010, p. 95). Critical and intellectual reflection is not exclusive to Philosophy and Literary Studies and is indispensable to any type of intellectual work.

\section{The Democracy Needs Us Defense}

Perhaps the most ambitious defense of the Humanities is the idea that the Humanities cultivate democratic sensibilities and it is essential for the success of democracy. This line of argument is often associated with the work of its most famous exponent Martha Nussbaum. Nussbaum's core argument-that a Humanities education cultivates sensibilities necessary for the success of democratic self-government-has been repeatedly invoked, to the point of deafening banality, in current debates on the value of the Humanities. As a claim that appeals to practical reason, it responds directly to demands for the Humanities to justify their relevance-unlike the other enduring defense of the Humanities as necessarily (and even admirably) useless, intrinsically devoid of practical and economic utility. However, it could be argued that the persuasiveness of Nussbaum's approach draws not so much from its originality, but more from its timely appearance. Shortly after her book was published, the world saw the global rise of various authoritarian personalities seemingly affirming her diagnosis. Indeed, it seems that in neglecting to address the symptoms, we now find ourselves in the advanced stages of the cancer that 
5 "...and beyond/ Frighted the reign of Chaos and old Night": On the Humanities (in times of) Crisis

Nussbaum had warned us about. So, it is tempting to think that the global crisis of democracy was in some way a consequence of the Humanities crisis. The idea that the return and rise of authoritarian personalities could have been prevented had democratic governments defended rather than defunded the Humanities offers perverse vindication to supporters of the field. If we had only cultivated enough democratic sensibilities in the populace through the Humanities, then perhaps populists would not have been able to charm their way into power. Indeed, the force of Nussbaum's argument stems in part from the perception that it responds to a historical emergency. Thus, the Humanities, so often vague in articulating their use-value, find in the present moment of crisis a clear purpose: they are the defenders of democracy at a time when it seems to be in crisis. This argument is currently being echoed with considerable force in current debates in the public sphere, with slightly different iterations that speak to the current crisis of democracy. For example: there are those who suggest that a lack of Humanities training may make one more susceptible to fake news and disinformation (Hampton 2018; Baker 2019). This idea exposes the extent to which the Humanities crisis is entangled in the crisis of democracy and historicizes claims made on behalf of the Humanities and their meaningful contribution to the strengthening of democratic capacities. While the notion that education contributes positively to political life has a long history, the idea that the Humanities are privileged among other subject areas in the formation of responsible civic consciousness is a more recent claim. As Small notes, many of the Victorian figures one is likely to associate with the liberal arts tradition (such as Arnold, Mill, Newman, and Ruskin) did not think that

... the arts and humanities had a privileged, let alone primary, role to play in training people for civic responsibility, though they reserved a vital place for them in the pursuit of happiness. (2013, p. 134)

While the "democracy needs us" claim might do well at the level of general piety, problems arise upon closer scrutiny. Small points out that Nussbaum's approach is beset by the "immediate problem of access" (2013, p. 132). For example, in the Philippines, tertiary enrolment in 2017 is at $35.28 \%$ (World Bank 2018). To be factored also would be the diminishing percentage of those who major in the Humanities. The irony here is that even if it were true that the Humanities could prepare students for democratic citizenship, access to education has not been democratized enough for them to make a meaningful impact. Probing further, however, there is an undemocratic core in what Small has identified as a "guardianship model" of democracy at work in Nussbaum's approach. Does not Nussbaum's guardianship model of democracy lack faith in the capacity of ordinary people? It seems to suggest that the success of democracy lies in the hands of the enlightened few to help the populace contain their "primitive shame" (Nussbaum, 2010, p. 32) and "projective disgust" (Nussbaum, 2010, p. 33) that may erupt as undemocratic tendencies. The problem with this idea, as the work of Jacques Rancière has shown, is that it makes equality a telos rather than an axiom (insofar as the axiom of equality also presupposes equality of intelligence). There is still fear of the Other: the fear of the other who is stupid. My disagreement with Nussbaum's argument is more fundamental. I am not simply echoing an old accusation of elitism in the Humanities (the training in the judgment of taste to align one's sensibilities to those of the ruling class); rather, I am more concerned that it might even cultivate, to use a phrase by Rancière, a "hatred of democracy" (2006, p. 2).

\section{Conclusion}

In closing, I have to once again ask a question that I am unable to answer: what will the future look like? It is difficult to tell, as difficult as it is to feel optimism of the non-cruel and nonwoeful variety. If neither the past nor the present escapes the distortion of regimes of power and 
calculation, the future remains both intangible and incalculable, but these are things that the Humanities have always engaged rather than recoiled from. It is, paradoxically, the uncertain future is what guarantees the enduring and undeniable value of the Humanities.

\section{References}

Adorno, T. (1991). “On Lyric Poetry and Society.” In Notes to Literature Vol. 1 (S. W. Nicholsen, Trans.). New York, NY: Columbia University Press. (Original work published 1958)

Arnold, M. (2006). Culture and Anarchy. Oxford: Oxford University Press. (Original work published 1869)

Butler, J. (2014). “Ordinary, Incredulous.” In P. Brooks \& Hilary Jewett (Eds.), The Humanities and Public Life (pp. 27-28). New York, NY: Fordham UP.

Collini, S. (2012). What are Universities for? London and NY: Penguin.

Derrida, J. “University without condition” - Without alibi

Fish, S. (2010, October 2). Crisis of the Humanities II. The New York Times. Retrieved from https://opinionator.blogs.nytimes.com/2010/10/18/crisis-of-the-humanities-ii/

Menand, L. (2010). The Marketplace of Ideas. NY: Norton.

Nussbaum, M. (2010). Not for Profit: Why Democracy Needs the Humanities. New Jersey: Princeton University Press.

Readings, B. (1996). The University in Ruins. Cambridge, MA: Harvard University Press.

Small, H. (2013). The Value of the Humanities. Oxford, UK: Oxford University Press.

Snow, C.P. (1963). The Two Cultures. Cambridge, UK: Cambridge UP.

Spivak, G. (2012). An Aesthetic Education in the Era of Globalization. Cambridge, MA: Harvard University Press.

Rancière, J. (2006). The Hatred of Democracy (S. Corcoran, Trans.). London \& New York: Verso. (Original work published 2005)

Zakaria, Fareed. (2015). In Defense of a Liberal Education. New York \& London: W.W. Norton \& Company.

Jeremy De Chavez is an Assistant Professor of English Literature at the University of Macau. His work has found print in journals such as JMMLA, The Explicator, ANQ, Food, Culture, \& Society, and Critical Arts. While his research and teaching areas are primarily in Postcolonial Studies, Global Anglophone Literature, and Critical/Cultural Theory, he is committed to being a strategic generalist with wide-ranging interests across literary periods, genres, and cultural forms. His forthcoming book Positive Affects and Postcolonial Critique is under contract with Routledge. 